\title{
Isolation and characterization of piperine from the fruits of black pepper (Piper nigrum)
}

\author{
K. C. Saha*, H. P. Seal and M. A. Noor \\ Department of Agricultural Chemistry, Bangladesh Agricultural University, Mymensingh-2202, Bangladesh \\ *E-mail: kartikchem@yahoo.com
}

\begin{abstract}
Black pepper (Piper nigrum) is a spice vine crop which is used as a food preservative and as an essential component in traditional medicines. The aim of this study was to extract, isolate and characterize the structure of piperine. The fruits of black pepper were extracted in ethanol and compounds present identified by TLC under iodine vapour. A compound $\left(A_{2}\right)$ having $R_{f}$ value 0.54 was isolated by column chromatography which may be responsible for the pungency of black pepper. After recrystallization of the isolate with benzene and chloroform mixture (7:1) gave pale yellow crystals of m.p. $128 \sim 129^{\circ} \mathrm{C}$ (reported $130^{\circ} \mathrm{C}$ ). The IR, ${ }^{1} \mathrm{H}$ NMR and mass spectra of the pure crystalline compound $\left(A_{2}\right)$ were recorded. The mass spectra of the compound $\left(A_{2}\right)$ showed molecular ion peak $M^{+\cdot}$ at 284.5 which was similar to that of piperine (mol. wt. 285).
\end{abstract}

Keywords: Piperine, TLC, IR, NMR, Mass spectrometry

\section{Introduction}

Black pepper (Piper nigrum) belongs to the family Piperaceae. It is cultivated for its fruit, which is usually dried and used as a spice and seasoning. Black pepper is known as king of spices and extensively used all over the world. It is a perennial climber, climbing by means of ivy-like roots which adhere to the support tree. The sessile, small white flowers are borne in pendulous, dense, slender spikes of about 50 blossoms each. The berry-like fruits or peppercorns are round about $0.5 \sim 1.0 \mathrm{~cm}$ in diameter and contain a single seed. They become yellowish-red at maturity and bear a single seed. Spike length varies greatly based on cultivar. The young berries are green, whitish green or light purple, while mature ones are green, pale purple or pale yellow and change to red on ripening.

Actually, piperine was isolated in good yield from ground black pepper by Oerstedt H Schweigers in 1821. Pepper's pungency was found in 1821 to be due to piperine. Historically, it has been thought to cure many illnesses such as cancer, malaria and cholera (Epstein et al., 1993).

Agrawal and Patwardhan (1994) reported that piperine present in black pepper fruit has antimicrobial activity. Jagella and Grosch (1999) reported that there are some compounds in black pepper fruit which are flavored and off flavored and inhibit the growth of Sclerotium rolfsi and Fusarium solani completely. Pradhan et al. (1999) studied the antimicrobial activity of black pepper fruit extract against some microorganisms and found that phenolic compounds present in the black pepper fruit extract. They found that black pepper fruit extract control the microorganisms. Sumathykutty and Madhusudana (1999) reported that some oil like compounds present in pepper are very effective to control Phomopsis vsexans. Strunz and Finlay (1994) synthesized pipercide a pesticidal unsaturated amide from black pepper fruit. Weaver and Neale (1988) studied the method for determination of piperine from black pepper fruit and they found that piperine present in black pepper fruit extract. De et al. (2000) reported that a chemical compound present in black pepper fruit, the name of the chemical compound is piperine. Piperine has fungicidal and insecticidal activity. Rajinder et al. (2002) studied the mode of action of piperine. Through human liver microsomal studies, they established that piperine, a major constituent of black pepper, inhibits human P-glycoprotein. 


\section{Materials and Methods}

The work was performed at the Organic Chemistry laboratory, Department of Agricultural Chemistry, BAU, Mymensingh.

\section{Preparation of black pepper fruit powder}

Dried black pepper fruits were purchased from local market at Mymensingh, cleaned to free from stone and other undesirable matters and sun dried. Then the sun dried fruits were ground in an electrically operated grinder to fine particle size. Extraction and isolation were performed according to the method described by Lambein et al. (1993).

Thin layer chromatography was carried out on glass plates coated with silica gel G type 60 . The different column chromatographic fractions of ethanolic extract were analysed with the help of thin layer chromatographic technique.

\section{Results and Discussion}

A column chromatographic fractions of benzene-EtOAc (3:1) were concentrated under vacuum and then recrystallized from benzene and chloroform mixture $(7: 1)$. This afforded pale yellow crystals of compound $\mathrm{A}_{2}$ (probably piperine) $(\sim 5 \mathrm{~g}$, yield $1.5 \%)$ m.p. $128 \sim 129^{\circ} \mathrm{C}$ (reported $130^{\circ} \mathrm{C}$ ). The probable structure of the pure crystalline compound $A_{2}$ was established by spectroscopic analysis like IR, ${ }^{1} \mathrm{H}$ NMR and mass spectrometry (Madhavi et al., 2009).

\section{Infra Red (IR)}

IR spectroscopy provides a fast and effective way to identify functional groups present in a molecule by looking to absorptions (bands) corresponding to the bond types present in the functional groups. The infrared absorption stretching of different bonds/functional groups of compound $A_{2}$ are tabulated in Table 1.

Table 1. The infrared stretching vibration for various bonds of compound $A_{2}$ (piperine)

\begin{tabular}{|l|c|c|}
\hline Type of vibration of different bonds & Observed frequency $\left(\mathrm{cm}^{-1}\right)$ & ${ }^{*}$ Reference frequency $\left(\mathrm{cm}^{-1}\right)$ \\
\hline Aromatic $\mathrm{C}-\mathrm{H}$ stretching & 3008.7 & above 3000 \\
\hline Aliphatic $\mathrm{C}-\mathrm{H}$ stretching & 2920 & 2925 \\
\hline$-\mathrm{CO}-\mathrm{N}$ stretching & 1699 & 1700 \\
\hline$-\mathrm{O}-\mathrm{CH}_{2}-\mathrm{O}-$ symmetric stretching & 1253 & - \\
\hline$-\mathrm{O}-\mathrm{CH}_{2}-\mathrm{O}-$ asymmetric stretching & 1134 & - \\
\hline Symmetric stretching of conjugated diene & 1633 & 1610 \\
\hline asymmetric stretching of conjugated diene & 1612 & 1000 \\
\hline$-\mathrm{C}-\mathrm{H}$ bending & 1018 & \\
\hline
\end{tabular}

*P. S. Kalsi, (2004)

The presence of aromatic $\mathrm{C}-\mathrm{H}$ stretching showed an absorption above $3000 \mathrm{~cm}^{-1}$ and around $2925 \mathrm{~cm}^{-1}$ for aliphatic $\mathrm{C}-\mathrm{H}$ stretching. Our finding agreed with the reference data (Table 1).

A strong absorption band in the region around $1700 \mathrm{~cm}^{-1}$ is due to the $\mathrm{C}=\mathrm{O}$ stretching and the presence of this band indicates that the ketonic group $(>C=O)$ may be present in the compound. Compound $A_{2}$ showed absorption at $1699 \mathrm{~cm}^{-1}$ which indicating the presence of ketonic ( $>\mathrm{C}=0$ ) group.

An ether group (methylene ether, $-\mathrm{O}_{-} \mathrm{CH}_{2}-\mathrm{O}-$ ) is distinctly clear from the strong band at $1230 \mathrm{~cm}^{-1}$ where as the experimental data found at $1253 \mathrm{~cm}^{-1}$ and $1134 \mathrm{~cm}^{-1}$ for symmetric and asymmetric stretching of the same ether group respectively. 
The symmetric and asymmetric stretching absorption bands at $1633 \mathrm{~cm}^{-1}$ and $1612 \mathrm{~cm}^{-1}$, respectively were observed for conjugated diene and the reference value was $1610 \mathrm{~cm}^{-1}$ which indicate the presence of conjugated diene in the compound.

Besides the $\mathrm{C}-\mathrm{H}$ bending for trans $-\mathrm{CH}=\mathrm{CH}-$ was observed at $1018 \mathrm{~cm}^{-1}$ which nearly same with that of reference data at $1000 \mathrm{~cm}^{-1}$.

\section{${ }^{1} \mathrm{H}$ NMR}

The compound $A_{2}$ isolated by column chromatography from the ethanolic extract of black pepper fruitpowder and was analysed by proton magnetic resonance ( ${ }^{1} \mathrm{H}$ NMR) spectrometry.

Every type of proton has only a limited range of $\delta$-values over which it gives resonance. Hence the numerical value in $\delta$-units of the chemical shift for a proton gives a clue as to the type of proton originating the signal.

The ${ }^{1} \mathrm{H}$ NMR spectrum in $\mathrm{CDCl}_{3}$ was recorded at $400 \mathrm{MHz}$ spectrophotometer and TMS (Tetramethylsilane) used as an internal standard.

The chemical shift values of protons in different environment of compound $A_{2}$ are tabulated in Table 2 and the spectrum shown in Fig. 1.

Table 2. The ${ }^{1} \mathrm{H}$ NMR data of compound $\mathrm{A}_{2}$ (piperine) in $\mathrm{CDCl}_{3}$

\begin{tabular}{|l|c|c|c|}
\hline Type of proton & $\begin{array}{c}\text { Number of proton } \\
\left({ }^{1} \mathrm{H}\right)\end{array}$ & $\begin{array}{c}\text { Observed chemical shift } \\
\delta \text { in ppm }\end{array}$ & $\begin{array}{c}{ }^{*} \text { Reference } \\
\text { chemical shift } \delta \text { in ppm }\end{array}$ \\
\hline Cycloaliphatic & 10 & $1.54 \sim 1.62$ & $1.2 \sim 1.4$ \\
\hline Alkenic & 4 & $5.7 \sim 6.7$ & $4.6 \sim 5.9$ \\
\hline Aromatic & 3 & $6.65 \sim 6.93$ & $6.8 \sim 7.3$ \\
\hline $\begin{array}{l}\text { Methylene attached } \\
\text { to oxygen atoms }\end{array}$ & 2 & $3.49 \sim 3.59$ & $3.2 \sim 3.8$ \\
\hline
\end{tabular}

* P. S. Kalsi, (2004); Pavia et. al., (2006)

\section{Cycloaliphatic proton $(\mathbf{1 0 H})$}

The methylene hydrogens $\left(-\mathrm{CH}_{2}-\right)$ of cycloaliphatic ring containing nitrogen atom show chemical shift at $\delta$ $1.54 \sim \delta 1.62$ where the reference data to those of are found $\delta 1.2 \sim \delta 1.4$ (Pavia et al., 2006). The methylene proton $\left(-\mathrm{CH}_{2}-\right)$ shows resonance between methyl and methine hydrogen. Actually this shift is intermediate. The chemical shift of these protons is variable, depending not only on the chemical environment, but also on concentration, temperature and solvent.

\section{Alkenic proton $(4 \mathrm{H})$}

The alkenic protons show experimental chemical shift at $\delta 5.7 \sim \delta 6.7$ which is shifted to a little bit downfield in comparison to that of standard values at $\delta 4.6 \sim \delta 5.9$. It may be happened for our sample due to the effect of carbonyl $(>C=0)$ group attached to the alkenic carbon.

\section{Aromatic Proton (3H)}

Phenyl rings are so common organic group that it is important to reveal a few facts about nmr absorptions in compounds that contain them. The ring protons of a benzenoid system have resonance, near $7.3 \mathrm{ppm}$. This value of chemical shift is diagnostic. 
ARD, BCSIR, 1H spectrum, PJ-1 in CDCl3, Asaduzzaman, A.J

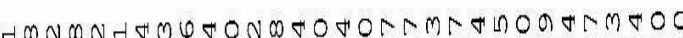
- w N W H H

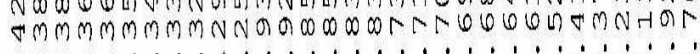

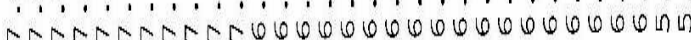

in $\quad$ and and

$\infty \infty$

0

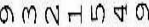

0000004

mM

nh4hH4h
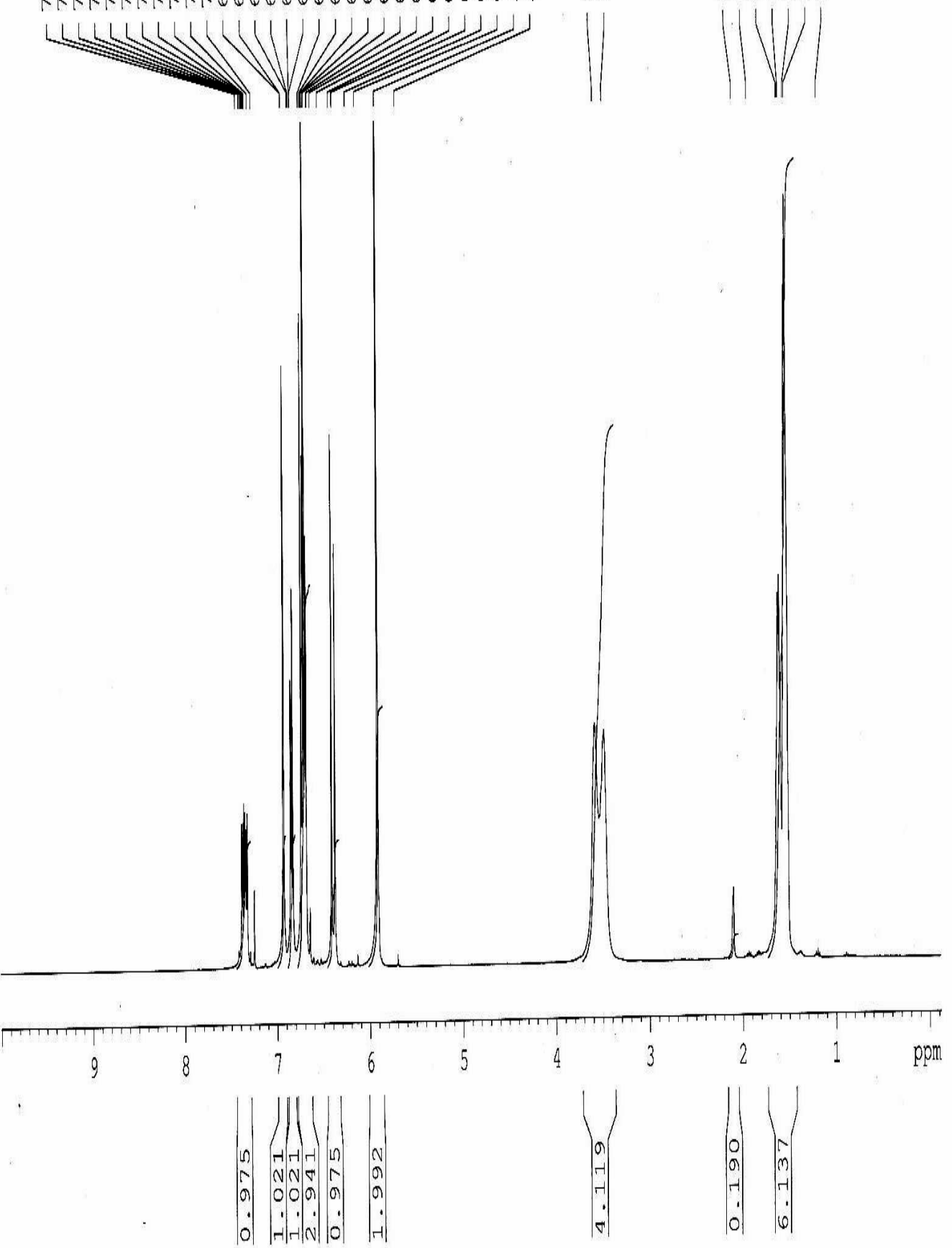

Fig. 1. $400 \mathrm{MHz}^{1}{ }^{1} \mathrm{NMR}$ spectrum of compound $\mathrm{A}_{2}$ (piperine) 
The aromatic compound gives only one aromatic peak (a singlet) in the proton nmr spectrum but that positions are affected more strongly than others in systems with substitution patterns different from this one. Here the electron donating substituent e.g. methoxy $\left(-\mathrm{OCH}_{3}\right)$ move the resonance of the ring protons upfield.

The compound $A_{2}$ gave chemical shift value $\delta 6.65 \sim \delta 6.93$ ppm for aromatic protons which showed a little bit upfield shift than that of reference data (Table 2). This deviation of chemical shifts of aromatic protons may happen due to presence of methylene dioxy group (-O- $\left.\mathrm{CH}_{2}-\mathrm{O}-\right)$ attached to the benzene ring (Pavia et al., 2006).

\section{Methylene dioxy proton (-O- $\left.\mathrm{CH}_{2}-\mathrm{O}-\right)$}

The chemical shift at $\delta 3.49 \sim \delta 3.59$ ppm was observed for the protons of methylne dioxy $\left(-\mathrm{O}-\mathrm{CH}_{2}-\mathrm{O}-\right)$ group. The hydrogen on the carbon attached to the oxygen are deshielded due to electronegativity of the oxygen. It is cited from the text that in ethers (R-O-CH-), the hydrogen on the carbon next to oxygen are deshielded for the above mentioned reason and they appear in the range $\delta 3.2 \sim \delta 3.8 \mathrm{ppm}$. The absorption of the methylene hydrogens next to the oxygen are seen at $\delta 3.4 \mathrm{ppm}$ (Pavia et al., 2006).

In methylene dioxy group, there are two hydrogens on the carbon attached to the two electronegative oxygen atoms. Therefore, the greater the electronegativity, the more it deshields protons and hence the greater is the chemical shifts of those protons.

\section{Mass spectrometry}

The mass spectra of compound $A_{2}$ clearly showed a molecular ion peak at $\mathrm{m} / \mathrm{z} 284.5$ corresponding to molecular formula, $\mathrm{C}_{17} \mathrm{H}_{19} \mathrm{NO}_{3}$ which is very nearly similar to the mass spectral data of piperine (Mol. wt. 285). Thus it may be concluded that the compound $A_{2}$ is piperine and its probable structure shown in Fig. 2.

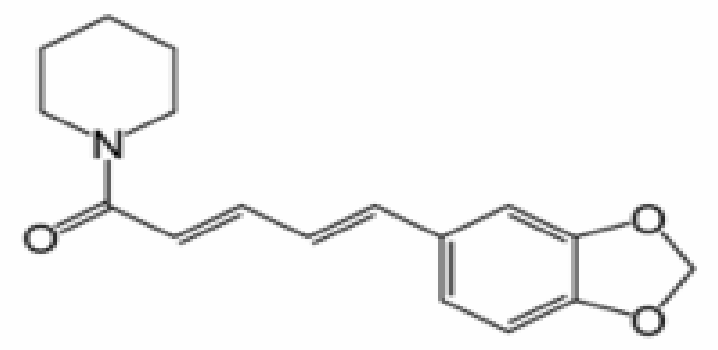

Fig. 2. Structure of piperine

\section{Acknowledgements}

The author expresses his sincere thanks to the Director of BAU Research system for financial assistance in favour of this research work and to the authority of B.C.S.I.R. laboratory, Dhaka for kind help to provide spectroscopic instrumental analysis (IR, NMR and Mass spectrometry).

\section{References}

Agrawal, R. and Patwardhan, M.V. 1994. Formation of piperine from in vitro culture of Piper nigrum L. Indian Journal of Plant Physiology, vol. 37(3), p-171 173.

Bindu Madhavi, B., Nath, A.R., Banji, D., Madhu, M.N., Ramalingam, R. and Swetha, D. 2009. Extraction, identification, formulation and evaluation of piperine in alginate beads. International J. of Pharmacy and Pharmaceutical Sciences, vol. 1, p-156.

De, P.V., Mark, N. and Abel, B.L. 2000. Synthesis and fungicidal insecticidal activity of new amide derivatives of piperine. Pest Management Science, vol. 56(2), p- 168 174.

Epstein, W.W., Netz, D.F. and Seidel, J.L. 1993. Isolation of Piperine from Black Pepper. J. Chem. Ed. vol. 70, p-598 599. 
Jagella, T. and Grosch, W. 1999. Flavour and off-flavour compounds of black and white black pepper (Piper nigrum L.). Desirable and undesirable odorants of white black pepper. Journal of European Food Research and Technology, vol. 209(1), $\mathrm{p}-27 \sim 31$.

Kalsi, P.S. 2004. Spectroscopy of Organic compounds (Sixth Edition). New Age International (P) Limited Publishers, New Delhi, Infrared spectroscopy, p-65 183.

Kalsi, P.S. 2004. Spectroscopy of Organic compounds (Sixth Edition). New Age International (P) Limitted Publishers, New Delhi, Proton nuclear magnetic resonance spectroscopy, p-216.

Lambein, F., Khan, J.K., Kuo, Y.H., Campbell, C.G. and Briggs, C.J. 1993. Toxin in the seedlings of some varieties of grasspea (Lathyrus sativus). Nat. Toxins., vol. 1, p-246 249.

Pavia, D.L., Lampman, G.M. and Kriz, G.S. 2006. Introduction to spectroscopy. A guide for students of Organic Chemistry. (New Edition), Harcourt College Publishers, India. p-122 256.

Pradhan, K.J., Bipul, P.S. and Variyar, M. 1999. Antimicrobial activity of novel phenolic compounds from green black pepper (Piper nigrum L.). Lebensmittel Wissenschaft and Technology, vol. 32(2), p-121 123.

Rajinder, K.B., Glaeser H., Becquemont L., Klotz U., Gupta K.S. and Fromm, F.M. 2002. Piperine, a major constituent of black pepper, inhibits human P-glycoprotein and CYP3A4. The Journal of Pharmacology and Experimental Therapeutics, vol. 302(2), p-645 650.

Strunz, G.M. and Finlay, H. 1994. Concise, efficient new synthesis of pipercide, an insecticidal unsaturated amide from Piper nigrum and related compounds. Tetrahedron, vol. 50(38), p-11113 11122.

Sumathykutty, M.A. and Madhusudana, R.J. 1999. Essential oil constituents of some Piper species. Flavour and Fragrance Journal, vol. 14(5), p-279 282.

Weaver, K.M. and Neale, M.E. 1988. Liquid chromatographic method for determination of piperine in Piper nigrum (black and white black pepper). Journal of the Association of Official Analytical Chemists, vol. 71(1), p-53 55. 